\title{
Correlation of clinical examination, ultrasound, magnetic resonance imaging and arthroscopy as diagnostic tools in shoulder pathology
}

\author{
Sondipan Biswas ${ }^{1}$, Naman Kanodia ${ }^{2}$, Rajat Tak ${ }^{2 *}$, Siddharth Agrawal ${ }^{2}$, Kiran Shankar Roy ${ }^{2}$
}

${ }^{1}$ Department of Orthopaedics, Dr. Baba Saheb Ambedkar Hospital, Rohini, New Delhi, India

${ }^{2}$ Department of Orthopaedics, Sir Ganga Ram Hospital, New Delhi, India

Received: 05 November 2019

Revised: 14 January 2020

Accepted: 16 January 2020

\author{
*Correspondence: \\ Dr. Rajat Tak, \\ E-mail: drrajattak06@gmail.com
}

Copyright: () the author(s), publisher and licensee Medip Academy. This is an open-access article distributed under the terms of the Creative Commons Attribution Non-Commercial License, which permits unrestricted non-commercial use, distribution, and reproduction in any medium, provided the original work is properly cited.

\begin{abstract}
Background: Shoulder pathologies can cause significant pain, discomfort, and affect the activity of daily living. The aim of this study was to compare the efficacy of clinical examination, ultrasound, magnetic resonance imaging (MRI) with shoulder arthroscopy in diagnosing various shoulder pathologies, considering shoulder arthroscopy as the gold standard tool.

Methods: This was a prospective, comparative study conducted over 35 patients, between 18-75 years of age presenting with chronic shoulder pain or instability of more than 2 months duration. All patients were examined clinically, followed by high resolution ultrasound, MRI, arthroscopy of the affected shoulder.

Results: The sensitivity and specificity of ultrasonography (USG) for diagnosing full thickness tear was $100 \%$ each and for MRI was $88 \%$ and $100 \%$ respectively. For subacromial impingement USG had sensitivity of $66.67 \%$, specificity of $94.12 \%$, positive predictive value of $50 \%$ and negative predictive value of $88.89 \%$. For rotator cuff tear USG had sensitivity of $92.86 \%$, specificity of $50 \%$, positive predictive value of $81.25 \%$ and negative predictive value of $75 \%$ considering shoulder arthroscopy as gold standard.

Conclusions: USG and MRI both are sensitive techniques for diagnosing of rotator cuff pathologies. USG has high accuracy in diagnosing partial thickness tears as compare to MRI. MRI proved to be superior in estimation of site and extent of tear. Considering shoulder arthroscopy as gold standard, it can be reserved for patients with suspicious of USG/MRI findings or those who may need surgical intervention simultaneously.
\end{abstract}

Keywords: Arthroscopy, MRI, Shoulder joint, USG

\section{INTRODUCTION}

Shoulder pain is third most common presenting complaints to an orthopedic surgeon after spine and knee pain. ${ }^{1}$ Rotator cuff pathologies specially tears constitutes most common cause of shoulder pain., ${ }^{2,3}$ Various pathologies of rotator cuff include tear, inflammation, impingement and instability. The rotator cuff is a group of four muscles and tendons that help to stabilize the shoulder joint. These are supraspinatus (superiorly), subscapularis (anteriorly), teres minor and infraspinatus (posteriorly). ${ }^{4}$ Rotator cuff failure occurs from tendinopathy that transforms from partial to complete thickness tears involving supraspinatus, infraspinatus and/or subscapularis tendon. ${ }^{5}$ Clinical examination provides less information in terms of diagnosis and treatment planning, hence imaging forms an integral part in evaluating these patients. Various imaging modalities includes high resolution ultrasound, magnetic resonance imaging (MRI), MR arthrogram. The advent of shoulder arthroscopy, in addition to the progress made in understanding the shoulder anatomy and biomechanics, 
has provided assistance to detect previously undiagnosed lesions. $^{6}$

ultrasonography (USG) and MRI both are widely used to assess rotator cuff pathology. The positive predictive value to diagnose shoulder pathology varies among UGS and MRI. Thus, considering shoulder arthroscopy as gold standard our study aim to correlate efficacy of clinical examination, ultrasound, MRI with shoulder arthroscopy as a diagnostic tool in shoulder pathology. Many diagnoses can be made upon clinical examination only, but to identify cause factor, type and extent of injury in rotator cuff tears, decision making in treatment whether conservative or surgical (open/arthroscopic) has made the imaging modalities superior to clinical examination.

USG of the shoulder is widely used as non-invasive, inexpensive, real time imaging modality. It is beneficial in the dynamic examination of the tendons during the

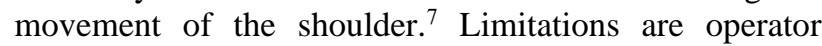
dependent, long learning curve. MRI is also non-invasive providing superior soft tissue resolution and considered as imaging of choice in detecting rotator cuff pathologies. $^{8-10}$ MR arthrography is superior in delineating intra-articular pathologies, but being invasive not preferred over plain MRI. Limitations include expensive, availability, time consuming, and absolute contraindications as cardiac pacemakers, aneurysmal clips, defibrillators etc.

The goal of the study was to correlate the clinical examination, ultrasound, MRI and arthroscopy as diagnostic tools in managing shoulder pathology.

\section{METHODS}

\section{Study design and patients}

This was a prospective, comparative study conducted over 35 patients, between 18-75 years of age presenting with chronic shoulder pain or instability of more than 2 months duration from December 2012 to October 2015 in department of orthopedic surgery, G.S.V.M. medical college, Kanpur. All patients were examined clinically, followed by imaging of the symptomatic shoulder. Patients with clinical diagnosis of shoulder instability (recurrent dislocation of shoulder), impingement syndrome (pain on lifting the arm), rotator cuff tear, tendinitis, superior labral (SLAP) tear, tear of long head of biceps tendon were included in the study. Patients with fracture/dislocation, infection, inflammatory arthritis were excluded from the study. Approval for the study was granted by the Institute Ethics Committee and was conducted according to the principles established in the Declaration of Helsinki. Consent for the publication of clinical, radiological details and photograph was obtained from the patients. High resolution USG and MRI were done by senior radiologist.
Ultrasonography of the shoulder was done using high resolution ultrasound machine with a high frequency 10 $\mathrm{MHz}$ linear ultrasound transducer [SonoSite ${ }^{\mathrm{TM}}$, Inc., Bothell, WA 98021, USA]. MRI was done by 1.5 tesla PHILIPS with sequences including axial T2WI, T2WI, PD fat saturation and coronal T2WI and T1WI with a wide range of MRI indices.

Arthroscopy was considered when conservative treatment failure for 6 months, or when rotator cuff was indicated.

\section{Ultrasonography technique}

USG of the shoulder was done using high frequency 10 $\mathrm{MHz}$ linear ultrasound transducer using musculoskeletal USG technical guidelines for shoulder of European society of musculoskeletal radiology. Position of the patient differs among institutions and examiners. USG of the shoulder was done in both static and dynamic positions.

\section{Long head of biceps tendon}

Arm was placed in internal rotation with 90 degrees flexed elbow and hand supinated. The bicipital groove was identified and tendon was seen between greater and lesser tuberosity. Normal tendon was seen as a uniform fibrillary structure. ${ }^{11}$

\section{Subscapularis tendon}

Arm was externally rotate with elbow resting on iliac crest, with palm facing upwards. This tendon was identified in transverse and sagittal planes with passive internal and external rotation. The subscapularis tendon is visible when entering medially to the groove. ${ }^{11}$

\section{Supraspinatus tendon}

The dorsum of hand was kept on the back with elbow opposed to the lateral wall of the chest. This position made tendon project anteriorly. Evaluation was done in both transverse and longitudinal planes. ${ }^{11}$

\section{Infraspinatus tendon}

The hand was kept at opposite shoulder. Supraspinous and infraspinous fossae were identified using spine as landmark. Probe was moved toward greater tuberosity in sagittal plane where teres minor and infraspinatus tendons are examined. ${ }^{11}$

\section{Subacromial impingement}

Dynamic assessment was done with arm abducted and internally rotated. Probe kept in coronal plane at the lateral margins of acromion.

Rotator cuff was assessed for the integrity, thickness and echo pattern. Following classification of rotator cuff tears 
was used no tear, partial thickness tear- articular side/bursal side and full thickness tear- with/without retraction.

USG findings in partial thickness tear- focal discontinuity/or focal thinning. USG findings in complete thickness tear can be lack of visualization of the tendon/ complete discontinuity/ or focal thinning.

On MRI increased signal intensity in platelet distribution width (PDW) images shows tendinopathy. Partial thickness tear was defined as focal increased signal intensity or discontinuity of fibers on T1W, PDW, T2W images. Complete tear is considered when discontinuity involves from bursal surface to articular surface with retraction of torn ends.

Clinical, USG and MRI diagnosis were placed into one of the four categories considering arthroscopy as gold standard and MRI superior over USG (categories are true positive, true negative, false positive, false negative). Collected data was presented in the form of tables. We calculated sensitivity, specificity, negative predictive value (NPV), positive predictive value (PPV).

\section{Statistical analysis}

Data was analyzed for the significant correlation between MRI of shoulder and USG by kappa coefficient. Sensitivity, specificity, PPV, NPV were calculated using cross tabulations. Chi square test were used to find the significance of MRI and USG findings. The $p$ value $<0.05$ was considered as statistically significant.

\section{RESULTS}

In this study, 35 patients were included. All of them were subjected to clinical evaluation, ultrasonography, MRI, arthroscopic examination of shoulder. The age of the patient ranged from 18-65 years. The mean age was 40.11 years. Maximum number of patients i.e., 10 (26.47\%) were of 21 to 30 years age group range. Out of 35 patients there were 31 males and 4 females. In the present study $22(61.76 \%)$ patients had right shoulder involvement. $29 \%$ (10) patients had spontaneous development of symptoms without history of trauma, while rest of $71 \%$ (24) patients had history of trauma around shoulder region.

Out of 35 patients, 27 patients were found to have rotator cuff tear on USG, 28 were found on MRI and 26 were positive in arthroscopy. Out of 27 patients, 17 patients were diagnosed with full thickness tear, 10 patients with partial thickness tear on USG. In MRI out of 28 patients, 15 were diagnosed with full thickness and 13 were diagnosed with partial thickness tear. 26 patients were found positive of rotator cuff tear on arthroscopy 17 patients were diagnosed with full thickness and 9 were diagnosed with partial thickness tear.

Percentage of false negative diagnosis by MRI when compared to clinical examination and arthroscopy was found to be $16.67 \%$. None of the patient was encountered to have any complications following arthroscopy.

Table 1: Total number of rotator cuff tear diagnosed on USG, MRI, arthroscopy.

\begin{tabular}{|llll|}
\hline \multirow{2}{*}{ Rotator cuff pathology } & USG & MRI & Arthroscopy \\
\hline Full thickness tear & N $(\boldsymbol{\%})$ & $\mathbf{N}(\boldsymbol{\%})$ & $\mathbf{N}(\boldsymbol{\%})$ \\
\hline Partial thickness tear & $17(63)$ & $15(53.5)$ & $17(65)$ \\
\hline Total patients & $10(37)$ & $13(46.5)$ & $9(35)$ \\
\hline
\end{tabular}

Table 2: Comparison between USG and clinical examination as a diagnostic tool in both arthroscopy and MRI group.

\begin{tabular}{|c|c|c|c|c|c|c|c|}
\hline $\begin{array}{l}\text { S. } \\
\text { no. }\end{array}$ & Diagnosis & $\begin{array}{l}\text { Gold } \\
\text { standard }\end{array}$ & Comparison & $\begin{array}{l}\text { Sensitivity } \\
(\%)\end{array}$ & $\begin{array}{l}\text { Specificity } \\
(\%)\end{array}$ & $\begin{array}{l}\text { PPV } \\
(\%)\end{array}$ & $\begin{array}{l}\text { NPV } \\
(\%)\end{array}$ \\
\hline \multirow{4}{*}{1.} & \multirow{4}{*}{$\begin{array}{l}\text { Supraspinatous } \\
\text { tear/tendinosis }\end{array}$} & \multirow[b]{2}{*}{ MRI } & USG & 37.5 & 100 & 100 & 33.33 \\
\hline & & & $\begin{array}{l}\text { Clinical } \\
\text { diagnosis }\end{array}$ & 75 & 100 & 100 & 56.56 \\
\hline & & \multirow{2}{*}{ Arthroscopy } & Clinical & 25 & 68.5 & 16.67 & 78.57 \\
\hline & & & diagnosis & 33.33 & 64.29 & 28.57 & 69.23 \\
\hline \multirow{4}{*}{2.} & \multirow{4}{*}{$\begin{array}{l}\text { Subscapularis } \\
\text { tear/tendinosis }\end{array}$} & \multirow[b]{2}{*}{ MRI } & USG & 50 & 89.47 & 33.33 & 94.44 \\
\hline & & & $\begin{array}{l}\text { Clinical } \\
\text { diagnosis }\end{array}$ & 100 & 89.47 & 50 & 100 \\
\hline & & \multirow[b]{2}{*}{ Arthroscopy } & USG & 30 & 60 & 42.86 & 46.15 \\
\hline & & & $\begin{array}{l}\text { Clinical } \\
\text { diagnosis }\end{array}$ & 37.5 & 75 & 50 & 64.29 \\
\hline
\end{tabular}




\begin{tabular}{|c|c|c|c|c|c|c|c|}
\hline $\begin{array}{l}\text { S. } \\
\text { no. }\end{array}$ & Diagnosis & $\begin{array}{l}\text { Gold } \\
\text { standard }\end{array}$ & Comparison & $\begin{array}{l}\text { Sensitivity } \\
(\%)\end{array}$ & $\begin{array}{l}\text { Specificity } \\
(\%)\end{array}$ & $\begin{array}{l}\text { PPV } \\
(\%)\end{array}$ & $\begin{array}{l}\text { NPV } \\
(\%)\end{array}$ \\
\hline \multirow{4}{*}{3.} & \multirow{4}{*}{$\begin{array}{l}\text { Impingement } \\
\text { syndrome }\end{array}$} & \multirow[b]{2}{*}{ MRI } & USG & 20 & 93.75 & 50 & 78.95 \\
\hline & & & $\begin{array}{l}\text { Clinical } \\
\text { diagnosis }\end{array}$ & 25 & 100 & 100 & 15 \\
\hline & & \multirow[b]{2}{*}{ Arthroscopy } & USG & 66.67 & 94.12 & 50 & 88.89 \\
\hline & & & $\begin{array}{l}\text { Clinical } \\
\text { diagnosis }\end{array}$ & 100 & 83.33 & 40 & 100 \\
\hline \multirow{4}{*}{4.} & \multirow{4}{*}{ Shoulder instability } & \multirow[b]{2}{*}{ MRI } & USG & 16.67 & 93.33 & 50 & 73.68 \\
\hline & & & $\begin{array}{l}\text { Clinical } \\
\text { diagnosis }\end{array}$ & 100 & 94.44 & 75 & 100 \\
\hline & & \multirow[b]{2}{*}{ Arthroscopy } & USG & 20 & 93.33 & 50 & 77.78 \\
\hline & & & $\begin{array}{l}\text { Clinical } \\
\text { diagnosis }\end{array}$ & 100 & 93.33 & 83.33 & 100 \\
\hline \multirow{4}{*}{5.} & \multirow{4}{*}{$\begin{array}{l}\text { Long head of biceps } \\
\text { tendinosis }\end{array}$} & \multirow[b]{2}{*}{ MRI } & USG & 50 & 89.47 & 33.33 & 94.44 \\
\hline & & & $\begin{array}{l}\text { Clinical } \\
\text { diagnosis }\end{array}$ & 100 & 89.47 & 50 & 100 \\
\hline & & \multirow[b]{2}{*}{ Arthroscopy } & USG & 25 & 81.25 & 25 & 81.25 \\
\hline & & & $\begin{array}{l}\text { Clinical } \\
\text { diagnosis }\end{array}$ & 33.33 & 85.71 & 50 & 75 \\
\hline
\end{tabular}

PPV- positive predictive value, NPV- negative predictive value.

\section{DISCUSSION}

USG and MRI have developed as new imaging techniques for shoulder pathologies in the past few decades. $^{12,13}$ In patients presenting with shoulder pain complaints, the aim is to diagnose whether the rotator cuff is intact or not with necessity to identify the torn tendon and to find extent of the tear. And treatment to be planned by the surgeon is depending on the accurate diagnosis. $^{7}$

With the development of new arthroscopic techniques for treating rotator cuff disorders, MRI has played an increasingly important role as a noninvasive test for determining which patients may benefit from surgery. ${ }^{4,9}$ A study by Lambert et al found the positive predictive value of 3.0T MRI to be $100 \%$ for the detection of rotator cuff tendon tears requiring surgery. ${ }^{14}$

With arthroscopy taken as gold standard for subacromial impingement USG had sensitivity of $66.67 \%$, specificity of $94.12 \%$, positive predictive value of $50 \%$ and negative predictive value of $88.89 \%$ in our study, while in study of Kiran et al ultrasonography had sensitivity of $79 \%$, specificity of $80 \%$, positive predictive value of $96 \%$ and negative predictive value of $76 \% .^{15}$

With arthroscopy taken as gold standard (Kiran et al, Burk et al) for subacromial impingement clinical examination had sensitivity of $100 \%$, specificity of $83.33 \%$, positive predictive value of $40 \%$ and negative predictive value of $100 \% .^{15,16}$

With arthroscopy as gold standard for rotator cuff tear/ tendinosis ultrasonography had sensitivity of $92.86 \%$, specificity of $50 \%$, positive predictive value of $81.25 \%$ and negative predictive value of $75 \%$ in our study, while in study of Al-Shawi et al ultrasonography had sensitivity of $96.2 \%$, specificity of $95.4 \%$, positive predictive value of $96 \%$ and negative predictive value of $95.4 \%$ and in study of Read et al ultrasonography had sensitivity of $46 \%$, specificity of $97 \%$, positive predictive value of $54 \%$ and negative predictive value of $80 \% .{ }^{17}$

With arthroscopy as gold standard Burk et al for unstable shoulder clinical examinations had sensitivity of $100 \%$, specificity of $93.33 \%$, positive predictive value of $83.33 \%$ and negative predictive value of $100 \% .{ }^{16}$

The most common diagnosis was rotator cuff tear, the similar findings were made in the study of Read et al. Percentage of false negative diagnosis by MRI when compared to clinical examination and arthroscopy was found to be $16.67 \% .^{17}$

The sensitivity and specificity of USG for diagnosing full thickness tear was $100 \%$ each and for MRI was $88 \%$ and $100 \%$ respectively. Full thickness tears are accurately diagnosed on both MRI and USG. Partial thickness tears misdiagnosed more in MRI as compare to USG, as USG can provide real time imaging. Chronic partial thickness tear can be missed on both USG and MRI.

There have been few studies comparing clinical examination with imaging and arthroscopic findings. Norregaard et al has shown a poor correlation between clinical examination comparing with USG and arthroscopy. ${ }^{18}$ Our study has found that impingement that were diagnosed with clinical signs have high accuracy in diagnosis in imaging as well as arthroscopically. 


\section{CONCLUSION}

Based on our results, it can be concluded that USG and MRI can be considered as an effective imaging modality in diagnosing the cause of shoulder pain and disability. USG and MRI both are sensitive techniques for diagnosing of rotator cuff pathologies. USG has high accuracy in diagnosing partial thickness tears as compare to MRI. Owing to its availability, cost and fast procedure USG can be used as a primary imaging method. MRI proved to be superior in estimation of site and extent of tear. Considering shoulder arthroscopy as gold standard, it can be reserved for patients with suspicious of USG/MRI findings or those who may need surgical intervention simultaneously.

Funding: No funding sources

Conflict of interest: None declared

Ethical approval: The study was approved by the institutional ethics committee

\section{REFERENCES}

1. Dinnes J, Loveman E, McIntyre L, Waugh N. The effectiveness of diagnostic tests for the assessment of shoulder pain due to soft tissue disorders a systematic review. Health Technol Assess. 2003;7(29):1-3.

2. Martin-Hervas C, Romero J, Navas-Acien A, Reboiras JJ, Munuera L. Ultrasonographic and magnetic resonance images of rotator cuff lesions compared with arthroscopy or open surgery findings. J Shoulder Elbow Surg. 2001;10(4):410-5.

3. van Holsbeeck MT, Kolowich PA, Eyler WR, Craig JG, Shirazi KK, Habra GK, et al.US depiction of partial-thickness tear of the rotator cuff. Radiology. 1995;197(5):443-6.

4. Bianchi S, Martinoli C. Ultrasound. Muscloskeletal Syst. 2007;12:246-56.

5. Lewis JS. Rotator cuff tendinopathy. Br J Sports Med. 2009;43(4):236-41.

6. Hegedus EJ, Goode AP, Cook CE, Michener L, Myer CA, Myer DM, et al. Which physical examination tests provide clinicians with the most value when examining the shoulder? Update of a systematic review with meta-analysis of individual tests. Br J Sports Med. 2012;46(14):964-78.

7. Al-Shawi A, Badge R, Bunker T. The detection of full thickness rotator cuff tears using ultrasound. $\mathrm{J}$ Bone Joint Surg Br Vol. 2008;90(7):889-92.
8. Iannotti JP, Zlatkin MB, Esterhai JL, Kressel HY, Dalinka MK, Spindler KP. Magnetic resonance imaging of the shoulder: sensitivity, specificity, and predictive value. J Bone Joint Surg Am. 1991;73(1):17-29.

9. Kneeland JB, Middleton WD, Carrera GF, Zeuge RC, Jesmanowicz A, Froncisz W, et al. MR imaging of the shoulder: diagnosis of rotator cuff tears. AJR Am J Roentgenol. 1987;149(2):333-7.

10. Singson RD, Hoang T, Dan S, Friedman M. MR evaluation of rotator cuff pathology using T2weighted fast spin-echo technique with and without fat suppression. AJR Am J Roentgenol. 1996;166(5):1061-5.

11. Martinoli C. Musculoskeletal ultrasound: Technical guidelines. Insights Imaging. 2010;1(3):99-141.

12. Middleton WD. Ultrasonography of the shoulder. Radiolclin North Am. 1992;30:927-40.

13. Alasaarela E, Takalo R, Tervonen O, Hkala M, Suramo I. sonography and MRI in evaluation of painful arthritic shoulder. Br J Rheumatol 1997; 36:996-1000.

14. Lambert, Loffroy R, Guiu B, Mejean, Lerais JM, Coffin JP, Krause D. Rotator cuff tears. Radiol J. 2009;190(5):583-8.

15. Ravi Kiran HG, Adnan Siddique P, Adarsh T, Vijay C, Mruthyunjaya SN. Functional outcome of arthroscopic subacromial decompression in primary shoulder impingement syndrome due to extrinsic mechanical causes. Int J Orthop. 2017;3(2):110-6.

16. Burk DL, Karasick DM, Kurtz AB, Mitchell DG, Rifkin MD, Miller CL. Rotator cuff tears: prospective comparison of MR imaging with Arthrography, Sonography and surgeries. AJR AM J Rientgenol. 1989;153:87-92.

17. Read JW, Perko M. Shoulder ultrasound: diagnostic accuracy for impingement syndrome, rotator cuff tear, and biceps tendon pathology. J Shoulder Elbow Surg. 1998;7(3):264-71.

18. Norregaard J, Krogsgaard MR, Lorenzen T, Jensen EM. Diagnosisng patients with longstanding shoulder joint pain. Ann Rheum Dis. 2002;61:646-50.

Cite this article as: Biswas S, Kanodia N, Tak R, Agrawal S, Roy KS. Correlation of clinical examination, ultrasound, magnetic resonance imaging and arthroscopy as diagnostic tools in shoulder pathology. Int J Res Orthop 2020;6:247-51. 